\title{
PENGEMBANGAN USAHA KECIL CETHOK DI KAMPUNG TEPI SUNGAI, BRATANG TANGKIS, SURABAYA
}

\author{
Priskila Adiasih \\ Program Studi Akuntansi, Fakultas Ekonomi, Universitas Kristen Petra \\ Jl. Siwalankerto 121-131, Surabaya, 60236 \\ *Korespondensi penulis, email: priskila@petra.ac.id
}

\begin{abstract}
Abstrak: Usaha kecil merupakan tulang punggung dari kampung informal di Perkotaan. Salah satu bentuk green business yang mendukung kampung informal Bratang Tangkis di Surabaya adalah usaha cethok komunitas. Cethok atau sendok ini digunakan untuk menunjang proses pengolahan kompos dengan metode takakura. Usaha ini mengolah bahan pipa polyvinylchlorida (PVC) bekas atau yang akrab dipanggil paralon. Usaha ini juga mengangkat ekonomi warga yang tergabung dalam usaha cethok komunitas sekaligus meningkatkan keberlanjutan dari kampung-kampung yang melakukan pengomposan ini. Untuk mendampingi pengembangan usaha ini maka dilakukan kegiatan SERVICE-LEARNING dalam kelas Sistem Informasi Bisnis, pada Program Studi Akuntansi, Program Akuntansi Bisnis. Kegiatan ini selain bertujuan untuk membantu usaha kecil ini juga diharapkan menjadi sarana bagi mahasiswa untuk meningkatkan kemampuan berinteraksi dengan warga, melakukan analisis SWOT, menyusun pembukuan sederhana, membantu promosi cethok melalui blog sehingga bermanfaat bagi warga untuk mengembangkan usaha cethok.
\end{abstract}

Kata kunci: Pipa paralon, cethok, analisis SWOT, pembukuan sederhana, blog.

\begin{abstract}
Recycling polyvinylchlorida pipe (PVC) or paralon to a trowel can be a tool to emerge from the economic downturn as well as forming cekom (cethok komunitas). Service learning activities by the Business Information Systems class is expected for students to improve their ability to interact with local community, to do a SWOT analysis, to develop a simple bookkeeping, to promote the trowel through a blog that is useful for the business community to develop their business.
\end{abstract}

Keywords: Pvc pipe, throwel, SWOT analysis, simple bookkeeping, blog.

\section{PENDAHULUAN}

Kampung Bratang Tangkis, adalah sebuah kampung informal di Surabaya yang terletak sekitar 800 meter sebelah timur Pintu Air Jagir di Kali Wonokromo. Warga Kampung Bratang Tangkis melalui wadah PWSS (Paguyuban Warga Stren Kali Surabaya), sudah memperjuangkan kepastian hukum akan lahan kampung dan menata kampung secara partisipatif serta mandiri. dengan konsep Jogo Kali (Menjaga Kali). Tetapi masih berjuang dengan isu kelayakan perumahan di kawasan ini. Usaha cethok merupakan salah satu bagian program penataan kampung ini.

Program perbaikan kampung (Rumah Contoh) di Bratang Tangkis telah dimulai sejak tahun 2005, dan mulai dibangun pada tahun 2008. Hal ini menyangkut perubahan orientasi rumah-rumah di Kampung ini menghadap sungai. Kemudian pembangunan di jalan inspeksi selebar 3-5 meter dengan merombak rumah-rumah yang ada. Kegiatan perbaikan ini didanai oleh tabungan swadaya Warga Kampung. Dan juga didukung oleh Urban Poor Consortium dan Perguruan Tinggi (termasuk Universitas Kristen Petra).

Dalam penataan fisik ini, dilakukan juga inisiatif upaya pengelolaan sampah organik dengan metode Keranjang Takakura. Upaya pengolahan ini didampingi oleh Pusat Pemberdayaan Komunitas Perkotaan (PUSDAKOTA), Universitas Surabaya. Pengolahan sampah organik ini yang menggunakan cetok dan keranjang ternyata membutuhkan pengadaan keranjang dan cethok. Cethok (sendok) untuk mengaduk kompos yang sudah ada ternyata kurang tahan lama karena terbuat dari besi dan mudah berkarat. Karena itu diperlukan cethok dari material lain yang lebih tahan lama. Hal ini ternyata memberikan usaha kecil yang bisa dilakukan oleh warga di antaranya Bapak Hariyono. 
Bapak Hariyono dan rekan-rekan kemudian mengembangkan usaha lewat acara-acara lingkungan hidup seperti "Ayo Merdeka dari Sampah" serta pelatihan Takakura. Bapak Hariyono mengembangkan ide untuk menciptakan cethok dari paralon bekas. Tentu saja produk cethok ini masih banyak kelemahan, tetapi berhasil dipasarkan kepada PUSDAKOTA, Universitas Surabaya. Setelah disempurnakan lagi, produk cethok ini akhirnya dapat dipasarkan lebih luas dan dipesan juga oleh lembaga-lembaga lain. Pesanan-pesanan tersebut mencapai volume 500-1000 buah cethok per pesanan. Karena tingginya permintaan ini, sebuah sistem produksi disusun secara sederhana dan yang dikerjakan bersama oleh warga Kampung Bratang Tangkis. Di sisi lain ternyata terdapat keterbatasan sistem pencatatan keuangan dan pemasaran yang berkelanjutan. Hal ini yang mendasari pengusulan kegiatan SERVICE-LEARNING dalam kelas Sistem Informasi Bisnis, pada Program Studi Akuntansi, Program Akuntansi Bisnis.

\section{TINJAUAN PUSTAKA}

Usaha kecil merupakan bagian penting dari ekonomi Indonesia, hal ini ditunjukkan dengan tingginya jumlah perusahaan kecil per kapita di Indonesia daripada di negara-negara lain (Kushnir et al., 2010). Secara historis perusahaan kecil atau dikenal sebagai Usaha Menengah Kecil dan Mikro (UMKM) adalah pemain utama dalam kegiatan domestik yaitu dalam penyediaan lapangan kerja, serta pengembangan ekonomi lokal dan masyarakat lokal. Bahkan UMKM juga berkontribusi terhadap ketahanan ekonomi negara selama krisis tahun 20082009. Di sisi lain, banyak UMKM masih terhambat untuk berkembang karena kurang kondusifnya lingkungan bisnis, sulitnya akses terhadap permodalan, terbatasnya akses ke pasar. Sehingga hal ini berdampak pada terhambatnya peningkatan standar hidup masyarakat lokal (Mouraougane, A., 2012).

Pilihan strategi dan kebijakan untuk memberdayakan UMKM diperlukan, terutama untuk memberikan pekerjaan baru kepada masyarakat lokal, serta mengembangkan dan menyeimbangkan pendapatan masyarakat lokal tersebut. Arus globalisasi telah mendorong UMKM untuk beradaptasi dengan cara memanfaatkan teknologi informasi. Salah satu peluang teknologi yang dapat digunakan adalah $E$ Commerce. Pemanfaatan teknologi informasi memungkinkan UMKM untuk promosi, mempercepat penerimaan pesanan pelanggan dan memasaran produk UMKM. E-Commerce dapat mengubah bentuk layanan sehingga pelanggan tidak harus datang ke tempat, menyediakan layanan pemesanan 24 jam, dan menyederhanakan semua transaksi (Kotler, 2009).
Pembiayaan UMKM adalah kendala berikutnya dalam usaha pengembangan atau investasi di UMKM. Survei UMKM oleh Bank Indonesia tahun 2014 menunjukkan bahwa semakin skala suatu usaha menurun semakin sulit akses pembiayaan bagi usaha tersebut. Hal ini juga didukung oleh Penelitian Beck, dkk (2006) di negara-negara berkembang lainnya. Akses terhadap kredit usaha ternyata sangat ketat bagi perusahaan kecil sector informal di Indonesia. Hal ini dapat diatasi dengan peningkatan standar laporan keuangan. Langkah ini diharapkan dapat meningkatkan akuntabilitas dan akhirnya meningkatkan akses UMKM terhadap sumber pembiayaan. Hal ini diakui karena laporan keuangan akuntansi meminimkan asimetri informasi kepada penyedia dana. Salah satu contoh standar yang dapat digunakan oleh UMKM adalah Standar Akuntansi untuk Entitas Tanpa Akuntabilitas Publik (ETAP).

\section{METODOLOGI}

Teknik observasi dan wawancara dilakukan oleh Dosen dan Mahasiswa dari Mata Kuliah Sistem Informasi Bisnis ke Kampung Bratang Tangkis. Observasi merupakan teknik/pendekatan untuk mendapatkan data primer dengan cara mengamati obyek data secara langsung sedangkan wawancara adalah komunikasi dua arah untuk mendapatkan data dari responden. Setelah mendapatkan data yang diperlukan, dilakukan analisa StrengthsWeaknesses - Opportunities - Threats (SWOT) atau Analisa Kekuatan-Kelemahan-Peluang-Ancaman bagi UMKM. Hasil dari proses ini ialah ini berupa laporan keuangan sederhana dan website promosi.

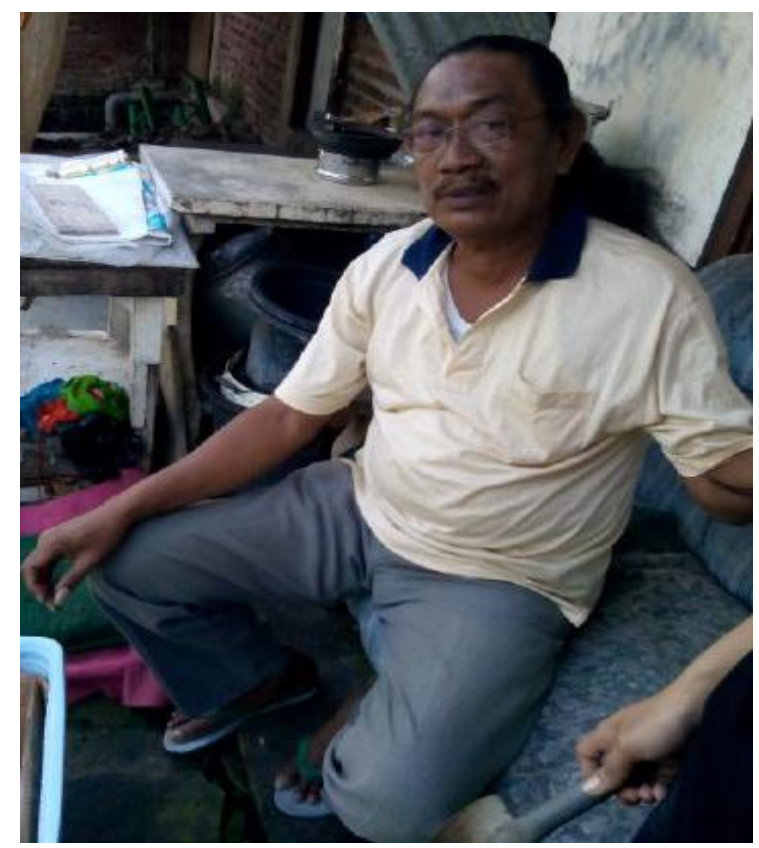

Gambar 1. Bapak Hariyono Karno, Pimpinan Kelompok Usaha cethok 


\section{DISKUSI DAN PEMBAHASAN}

Usaha cethok Pak Hariyono dan kawan-kawan dirintis sejak tahun 2006, dengan modal awal Rp. 300.000 ,- dan 50 orang tenaga kerja. Bahan baju produksi cethok ialah: pipa PVC, senar raket, penutup pipa belakang, paku, amplas, lem PVC, minyak tanah (untuk kompor pemanas). Beberapa alat yang dibutuhkan untuk produksi cetok antara lain gergaji, bor, kikir.

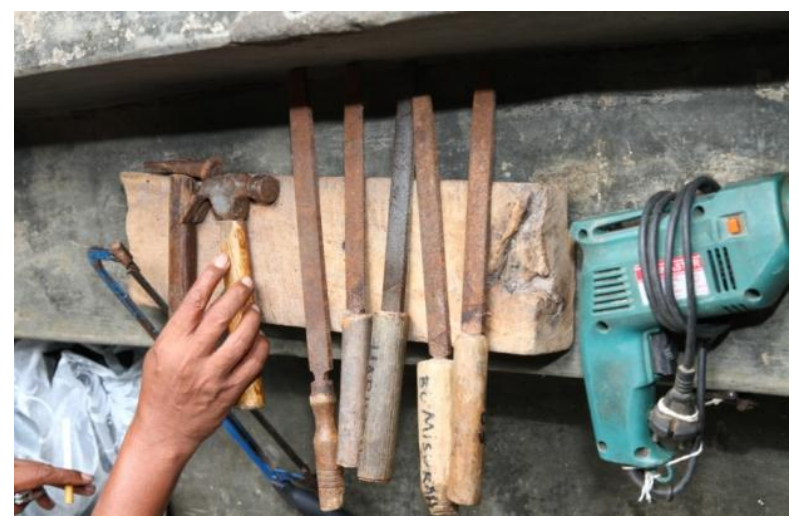

Gambar 2. Peralatan untuk Usaha Cetok

Tahapan-tahapan produksi cethok yang diperoleh dari observasi mahasiswa adalah sebagai berikut: penyalinan pola bagian sendok cethok; pemotongan bagian ujung dan pinggir sendok cethok; pengikiran dan pengamplasan pinggiran sendok cethok; pembersihan dan pemotongan pegangan cethok; penandaan batas belah dan pembelahan gagang cethok; penekanan (pressing) pegangan cethok; pemotongan pegangan cethok; pengikiran dan pengamplasan pinggiran sendok cethok; penyesuaian posisi; pengeboran batang; pengeleman gagang dan sendok; pemasangan baut keling; pemotongan tali dan pemasangan tali tutup pegangan cethok; pemasangan tutup pegangan cethok; pengguntingan label, pemasangan label; dan pengecekan kualitas.

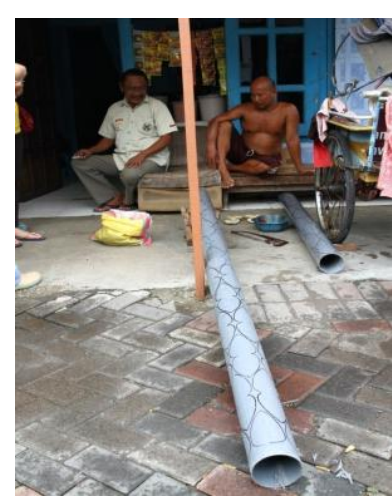

Gambar 3. Tahapan penyalinan pola bagian sendok cethok

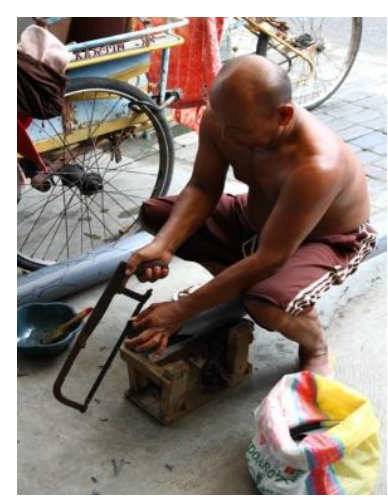

Gambar 4. Tahapan pemotongan bagian sendok cethok

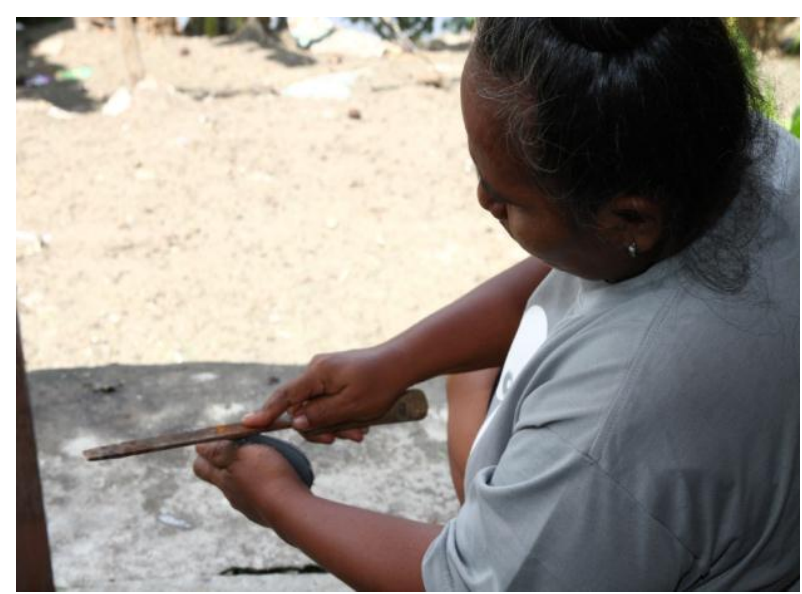

Gambar 5. Tahapan pengikiran dan pengamplasan pinggiran sendok cethok

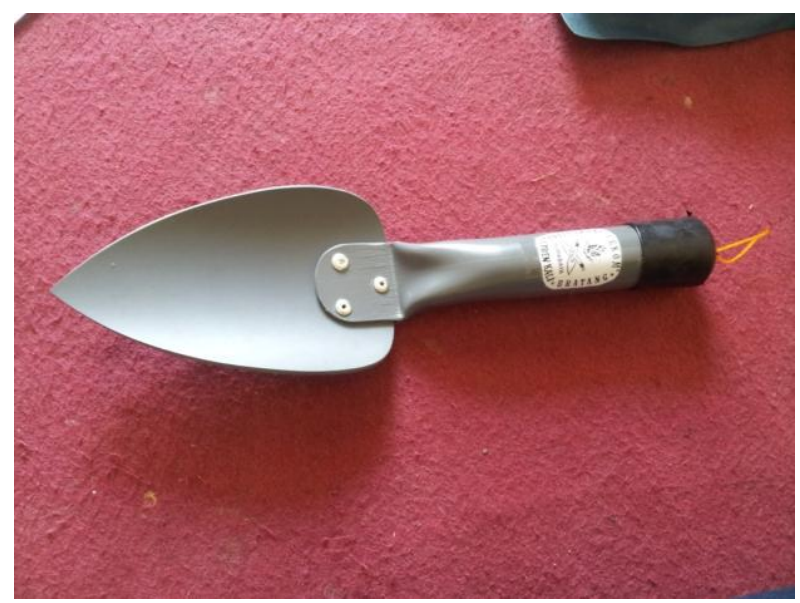

Gambar 6. Produk hasil akhir cetok

Dalam proses produksi, Pak Hariyono melibatkan beberapa warga kampung yang mengerjakan masing-masing tahapan di atas. Warga mengerjakan langkah-langkah ini di rumahnya atau pekarangannya masing-masing. Strategi ini dilakukan untuk membagikan kesempatan ekonomi di antara warga kampung yang ada. Sementara itu, Pak Hariyono berperan dalam penyelesaian (finishing) dan pengecekan kualitas (quality control) hasil cethok yang dihasilkan.

Dari pengamatan lapangan, ditemukan bahwa Bapak Hariyono telah melakukan pencatatan sederhana yang dilakukan tanpa dasar keilmuan akuntansi. Berdasarkan data dari pencatatan tersebut, Mahasiswa menyusun dan menyajikan kembali laporan akuntansi tersebut di Tabel 1 dan Tabel 2. Penyusunan dan penyajian kembali catatan ini bertujuan untuk melaporkan kelayakan usaha serta pengelolaan dana yang diperoleh (dari uang muka penjualan). 
Tabel 1. Tabel biaya bahan Usaha Kecil Kerajinan Cethok (untuk produksi 500 cethok)

\begin{tabular}{|c|c|c|c|c|}
\hline No & Nama Bahan & Jumlah & Harga Satuan (Rp) & Pengeluaran (Rp) \\
\hline & Pembelian Bahan-bahan: & & & \\
\hline 1 & 4 batang pipa pralon 4 inchi & 4 & 99,500 & 398,000 \\
\hline 2 & 25 batang pipa pralon $3 / 4$ inchi & 25 & 21,000 & 525,000 \\
\hline 3 & 11 rol tali plastik senar raket & 11 & 4,000 & 44,000 \\
\hline 4 & 550 biji tutup cop besar & 550 & 400 & 220,000 \\
\hline 5 & 1650 biji paku & 1650 & 80 & 132,000 \\
\hline 6 & $2 \mathrm{~m}$ kertas gosok merk norton & 2 & 7,500 & 15,000 \\
\hline 7 & 600 gram lem PVC & 600 & 110 & 66,000 \\
\hline 8 & 5 liter minyak tanah & 5 & 3,500 & 17,500 \\
\hline 9 & 50 lembar fotocopy label dan laporan & 50 & 100 & 5,000 \\
\hline 10 & 1 botol plastic tinta spidol snowman permanent & 1 & 6,500 & 6,500 \\
\hline 11 & 1 spidol kecil warna merah & 1 & 1,500 & 1,500 \\
\hline 12 & 1 buah isolasi bening untuk label & 1 & 7,400 & 7,400 \\
\hline 13 & 4 lembar benang laying - laying (glangsing) & 4 & 500 & 2,000 \\
\hline 14 & 1 buah buku laporan & 1 & 11,500 & 11,500 \\
\hline 15 & 1 buah mata gergaji sanplex & 1 & 8,500 & 8,500 \\
\hline 16 & 1 buah mata bor $3 \mathrm{~mm}$ & 1 & 8,000 & 8,000 \\
\hline \multirow[t]{2}{*}{17} & 1 kali angkut becak & 1 & 8,000 & 8,000 \\
\hline & Total & & & $1,475,900$ \\
\hline
\end{tabular}

Tabel 2. Tabel biaya tenaga kerja untuk Usaha Kecil Kerajinan Cethok (untuk produksi 500 cethok)

\begin{tabular}{|c|c|c|c|c|c|}
\hline No & Sub-Pekerjaan & $\begin{array}{l}\text { Nama Sub-Pekerjaan } \\
\text { menurut P Hariyono }\end{array}$ & Jumlah & $\begin{array}{c}\text { Harga } \\
\text { Satuan (Rp) }\end{array}$ & $\begin{array}{c}\text { Pengeluaran } \\
\text { (Rp) }\end{array}$ \\
\hline \multicolumn{6}{|c|}{ Pekerjaan } \\
\hline 1 & Penyalinan pola bagian sendok cethok & Mengemal daun & 500 & 40 & 20.000 \\
\hline 2 & Pemotongan pinggiran sendok cethok & Memotong daun & 500 & 170 & 85.000 \\
\hline 3 & Pemotongan bagian ujung sendok cethok & Memotong sudut daun & 500 & 40 & 20.000 \\
\hline 4 & Pengikiran pinggiran sendok cethok & Mengikir pinggiran daun & 500 & 200 & 100.000 \\
\hline 5 & Pengamplasan pinggiran sendok cethok & Menggosok pinggiran daun & 500 & 80 & 40.000 \\
\hline 6 & Pemotongan pegangan cethok & Memotong gagang & 500 & 40 & 20.000 \\
\hline 7 & Pembersihan pegangan cethok & Membersihkan gagang & 500 & 35 & 17.500 \\
\hline 8 & Penandaan batas belah gagang cethok & Menggaris gagang & 500 & 20 & 10.000 \\
\hline 9 & Pembelahan gagang cethok & Membelah gagang & 500 & 40 & 20.000 \\
\hline 10 & Penekanan (pressing) pegangan cethok & Mengepres gagang & 500 & 200 & 100.000 \\
\hline 11 & Pemotongan pegangan cethok & Memotong sudut gagang & 500 & 40 & 20.000 \\
\hline 12 & Pengikiran pinggiran sendok cethok & Mengikir gagang/ oval & 500 & 150 & 75.000 \\
\hline 13 & Pengamplasan pinggiran sendok cethok & Menggosok gagang & 500 & 80 & 40.000 \\
\hline 14 & Penyesuaian posisi & Nyetel & 500 & 50 & 25.000 \\
\hline 15 & Pengeboran batang & Ngebor & 500 & 125 & 62.500 \\
\hline 16 & Pengeleman gagang dan sendok & Ngelim & 500 & 25 & 12.500 \\
\hline 17 & Pemasangan baut keling & Dikeling & 500 & 125 & 62.500 \\
\hline 18 & Pemotongan tali tutup pegangan cethok & Potong tali dan membuat simpul & 500 & 50 & 25.000 \\
\hline 19 & Pemasangan tali tutup pegangan cethok & Pasang tali tutup & 500 & 50 & 25.000 \\
\hline 20 & Pemasangan tutup pegangan cethok & Pasang tutup & 500 & 35 & 17.500 \\
\hline 21 & Pengguntingan label & Menggunting label & 500 & 40 & 20.000 \\
\hline 22 & Pemasangan label & Memasang label & 500 & 40 & 20.000 \\
\hline 23 & Pengecekan kualitas & Cek kualitas & 500 & 100 & 50.000 \\
\hline \multicolumn{5}{|c|}{ Total } & 887.500 \\
\hline
\end{tabular}

Dalam penghitungan ini ternyata masing-masing cethok diproduksi dengan biaya dan harga jual seperti Tabel 3.

Tabel 3. Perbandingan antara Biaya Produksi dan Harga Jual

\begin{tabular}{lrr}
\hline Total Biaya Produksi untuk 500 cethok & $\mathrm{Rp}$ & $2,363,400$ \\
Biaya satuan produksi per cethok & $\mathrm{Rp}$ & 4,727 \\
Harga jual satuan per cethok & $\mathrm{Rp}$ & 7,000 \\
Keuntungan per cethok & $\mathrm{Rp}$ & 2,273 \\
\hline
\end{tabular}

Nampak dari perhitungan di atas, usaha cethok ini didapati cukup menguntungkan. Namun Nampaknya perlu ditelaah kembali keakuratan harga upah dan bahan-bahan dari produk ini agar laporan akuntansi ini lebih akurat. Selain itu diperlukan strategi bisnis termasuk pemasaran yang lebih berkelanjutan, mengingat tidak berlanjutnya kebutuhan cethok dari pasar. 
Tabel 4. SWOT untuk Usaha Komunitas Cethok Bratang Tangkis

\begin{tabular}{|c|c|}
\hline Strength (Kekuatan) & Weakness (Kelemahan) \\
\hline $\begin{array}{l}\text { - Kemauan keras dari Pak Hariyono dkk. sangat men- } \\
\text { dukung usaha ini, } \\
\text { - Jaringan pemasaran informal yang sudah cukup luas, } \\
\text { - Kemampuan desain dan pelaksanaan Bapak Hariyono } \\
\text { dan rekan - rekan yang sudah baik, }\end{array}$ & $\begin{array}{l}\text { - Perlunya ditelaah harga bahan dan upah dan } \\
\text { penyesuaian harga produk akhir agar usaha ini } \\
\text { menguntungkan } \\
\text { - Perlunya peningkatan strategi pengelolaan Sumber } \\
\text { Daya Manusia yang lebih baik, } \\
\text { - Perlunya strategi pemasaran bagi komunitas pencinta } \\
\text { lingkungan hidup yang berusia muda, } \\
\text { - Perlunya tempat usaha yang lebih memadai dan } \\
\text { aksesibel untuk Bapak Hariyono, } \\
\text { - Perlunya peningkatan peralatan yang lebih lengkap } \\
\text { agar produksi lebih baik kualitasnya, }\end{array}$ \\
\hline
\end{tabular}

\begin{tabular}{ll}
\hline \multicolumn{1}{c}{ Opportunity (Kesempatan) } & \multicolumn{1}{c}{ Threat (Ancaman) } \\
\hline - Munculnya komunitas pencinta lingkungan yang mau & • Munculnya saingan produsen cethok dengan desain \\
mengelola sampah menjadi kompos, & yang sama dan harga yang bersaing. \\
- Munculnya kebutuhan urban farming yang dapat & \\
diintegrasikan dengan kegiatan pengomposan dan usaha \\
cethok ini,
\end{tabular}

Setelah melakukan penghitungan biaya produksi cetok, tahapan selanjutnya adalah melakukan analisis SWOT untuk:

1. Memberikan informasi mengenai kondisi perusahaan, selanjutnya melalui informasi yang ada tersebut akan menjadi pedoman bagi komunitas untuk melakukan berbagai kebijakan baru sebagai solusi atas hasil analisa yang sudah ada.

2. Memberikan tantangan ide-ide baru bagi pihak komunitas. Adanya berbagai permasalahan seperti kelemahan, peluang serta kekuatan yang kecil ataupun ancaman dari pihak luar akan mendorong bagian komunitas untuk menemukan berbagai ide kebijakan yang lebih baru dan akan lebih efektif menjadi solusi atas berbagai permasalahan yang ada.

Salah satu usulan dari analisis SWOT ini adalah penyusunan website promosi. Mahasiswa kemudian berusaha membuat blog sederhana guna mempromosikan Kampung Bratang Tangkis dan usaha cetok masyarakat melalui blog http:/ / cetokkompos, blogspot.com/ dan http://welearningandsharing. blogspot.com/. Ternyata sampai saat ini dirasakan bahwa media pemasaran ini masih perlu dikembangkan mengingat masih belum dikenalnya produksi cethok ini secara nasional dan belum berlanjutnya pesanan dari pasar yang ada.

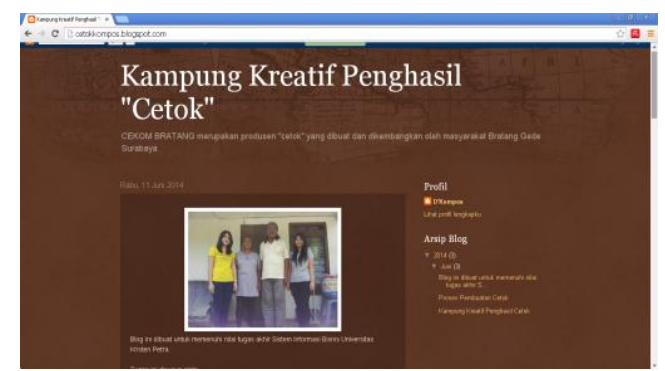

Gambar 7. Desain Website http://cetokkompos.blogspot. com/

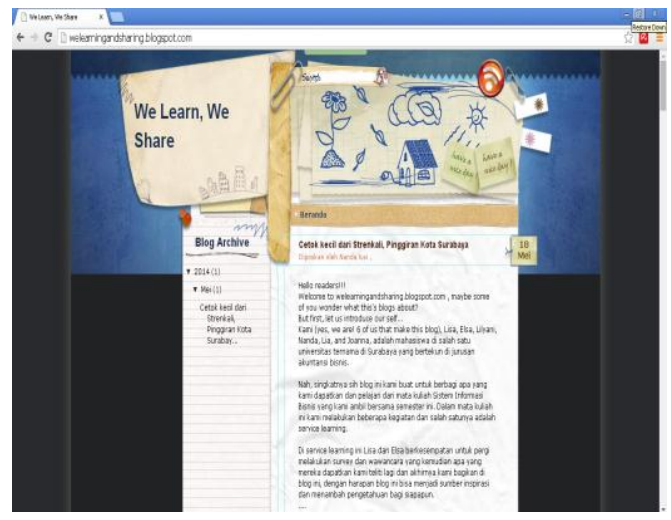

Gambar 8. Desain Website http://welearningandsharing. blogspot.com/

\section{KESIMPULAN}

Usaha cethok Bapak Hariyono ini telah menjadi salah satu potensi Green Business yang patut dibanggakan oleh Warga Kampung Tepi Sungai (Strenkali) Surabaya. Pelibatan 50 orang warga setempat kampung sebagai tenaga kerja merupakan strategi pengembangan ekonomi yang berkelanjutan bagi Kampung-Kampung (Informal) Tepi Sungai di Surabaya seperti Kampung Bratang Tangkis. Produksi cethok ini tetap dilakukan oleh warga walau menghadapi kelemahan dan hambatan seperti tempat produksi yang terbatas, peralatan yang sederhana, rendahnya pemasaran. Karena itu diperlukan pendampingan SERVICE-LEARNING untuk pembuatan laporan keuangan dan pemasaran produksi cetok. Langkah-langkah ini perlu dikembangkan lagi di masa depan agar Usaha Cethok Komunitas ini dapat berkembang dan mendukung terciptanya Green City (dalam Aspek Ekonomi, Sosial, dan Lingkungan). 


\section{DAFTAR PUSTAKA}

Beck, T., A. Demirgüc-Kunt, L. Laeven and V. Maksimovic (2006), "The Determinants of Financing Obstacles", Journal of International Money and Finance, Vol. 25, pp. 932-952.

Kotler, Phillip and Keller Kevin Lane, 2009. Marketing Management $13^{\text {th }}$, Edition Pearson Prentice Hall.

Kushnir, K., M. L. Mirmulstein and R. Ramalho (2010), "Micro Small and Medium Term Enter- prise around the World: How Many are There and What Affects the Count?', World Bank and IFC MSME Country Indicators.

Mourougane, A. (2012), "Promoting SME development in Indonesia", OECD Economics Department Working Papers, No. 995, OECD Publishing. http://dx.doi.org/10.1787/5k918xk464f7-en http://www.bi.go.id/id/publikasi/survei/kegiatandunia-usaha/Documents/SKDU-Tw\%20III2014.pdf, diakses pada 1 Oktober 2014. 